\title{
Silviculture can facilitate repeat prescribed burn programs with long-term strategies
}

\author{
Burn programs to reduce fuel loads in California forests are most effective when stand \\ characteristics and forest structure are considered.
}

by Robert A. York, Jacob Levine, Daniel Foster, Scott Stephens and Brandon Collins

Online: https://doi.org/10.3733/ca.2021a0016

\section{Abstract}

A significant expansion of prescribed fire activity will be necessary to mitigate growing wildfire hazard in California forests. Forest managers can facilitate this expansion by promoting forest structures that allow for more effective implementation of prescribed fire, for both initial-entry and repeat burns. We analyzed changes in surface fuel during a series of three burns in replicated mixed-conifer stands following a period of over 100 years of fire suppression and exclusion. Total fuel load, proportion of pine present, canopy cover and basal area of live trees were relevant forest-structure components that influenced plot-scale fuel consumption. The study highlighted the importance of pre-fire fuel load and the relative proportion of pine in the overstory, which both led to greater amounts of fuel consumption. The initial-entry burn dramatically reduced all fuel categories (fine fuel, coarse wood and duff). Following each burn, fuel recovered until the next burn reduced loads enough to maintain low fuel levels. We apply the results to provide an example of how to determine the timing of prescribed fires.
$\mathrm{O}$ ver the past century, exclusion of Indigenous and private land burning as well as aggressive fire suppression have drastically altered forest structure in many forest types throughout western North America, including mixed-conifer forests in California (Stephens et al. 2015). In the absence of frequent, low-intensity fires, today's mixed-conifer forests are characterized by greater fuel loads, more horizontal and vertical fuel continuity, increased tree density, smaller average tree diameter and a shift in composition toward shade-tolerant species (Miller and Urban 2000; Scholl and Taylor 2010). The sum effect is a marked increase in the risk of high-severity wildfire (Taylor et al. 2013), resulting in unprecedented timber losses, property damage, injury and human death (Cal Fire 2018).

To reduce these risks, forest managers intentionally set controlled, or prescribed, fires in forests adapted to frequent fire (Fernandes and Botelho 2003; Ryan et al.

By understanding the effects of stand characteristics on fuel consumption, prescribed burns can be prioritized to occur where consumption is expected to be greatest. The burn in this photo was done opportunistically during a dry period in December of 2020. Photo: Rob York.

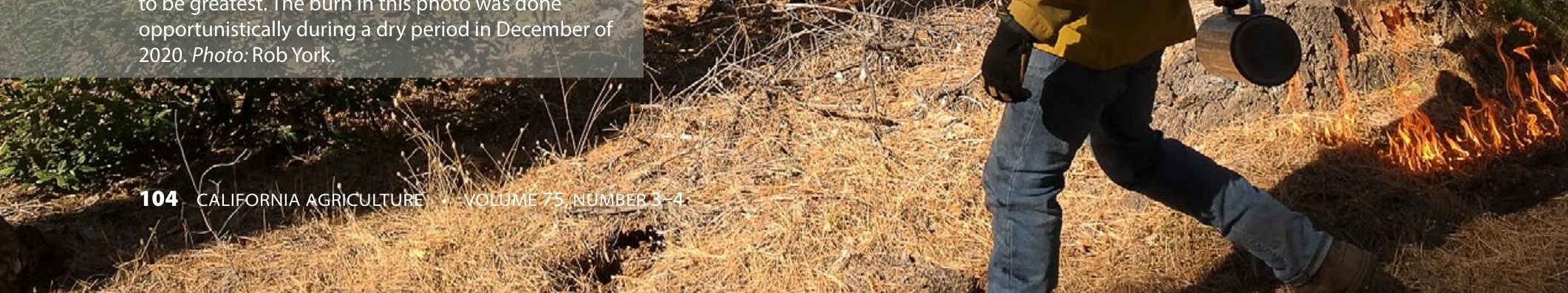


2013). Prescribed fires consume surface fuels, primarily litter, woody debris, small trees, and brush. However, fuel consumption in prescribed fires can be highly variable both within and between burns. The amount of fuel consumed is dependent on two major conditions: weather, including precipitation and resulting fuel moisture, and forest stand characteristics, such as species composition and canopy density. While the influence of weather-dependent conditions on fuel consumption is relatively well understood, the influence of stand characteristics is not (Knapp et al. 2005; Vaillant et al. 2009). Stand structures are highly dependent on past silvicultural practices and on the time that has passed since the last disturbance. By understanding the effects of stand characteristics on fuel consumption, prescribed burns can be prioritized to occur where consumption is expected to be greatest. Likewise, current silvicultural practices can be adjusted to facilitate improved fuel consumption in future burns.

\section{(A)}

Ratcheting down

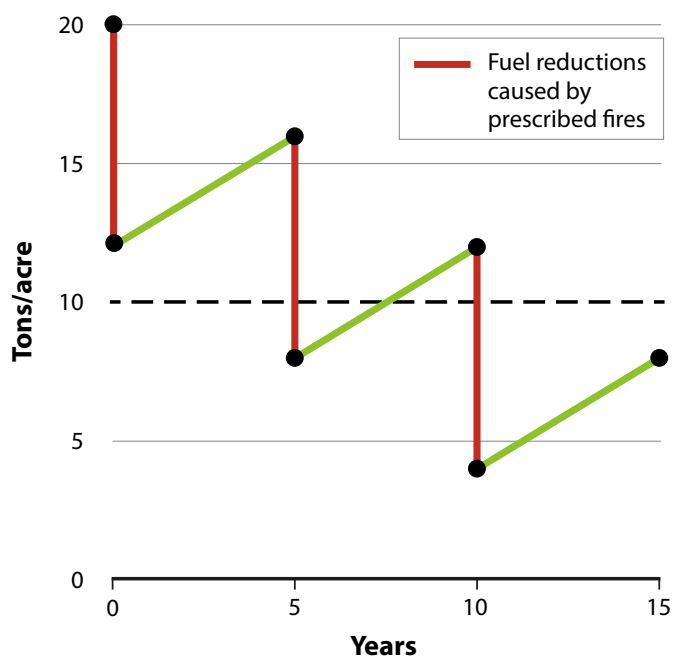

(C) Small drop and maintenance

25
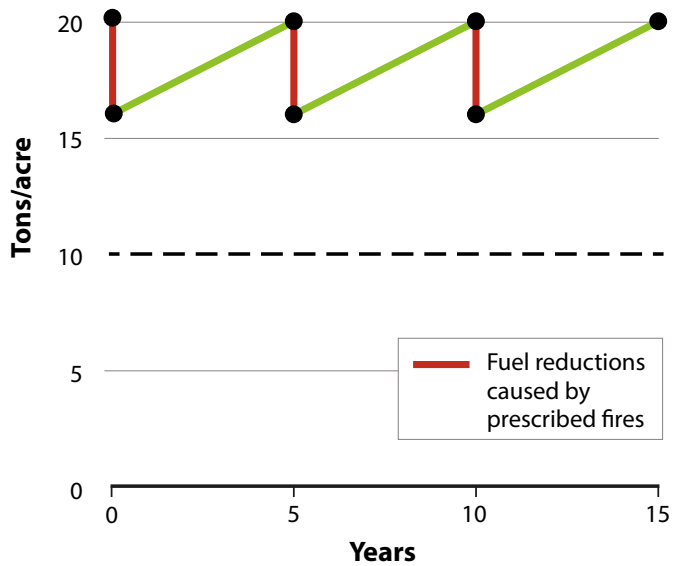

\section{Burn programs: a tiered approach}

Conducting initial burns where fire has not occurred for numerous decades is a critical step toward reintroducing the ecological process of fire into California forests, but second- and third-entry burns are necessary to achieve more complete fire restoration (Webster and Halpern 2010). As prescribed fire use increases in California, so will the proportion of prescribed fires that are repeat burns. The results from a series of burns, rather than the effect of any individual burn, will ultimately determine a burn program's success. By burn program, we refer to the decisions regarding the timing, frequency and size of prescribed fires. Depending on the details of these decisions, a number of different fuel-dynamics patterns may occur (fig. 1). Given the considerable amount of surface fuels that have accumulated during the long period without fire in many California forests, it is not clear how fuel consumption in initial-entry burns will differ from that in repeated

\section{(B) Large drop and maintenance}

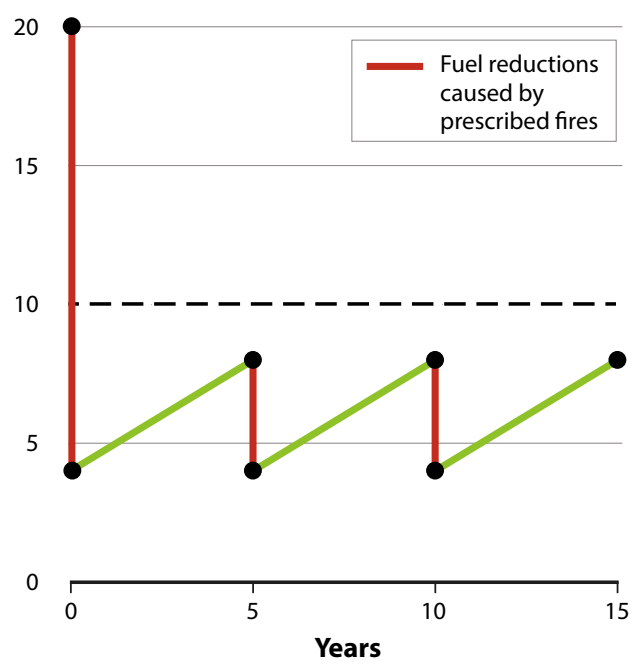

(D) Large drop and low frequency

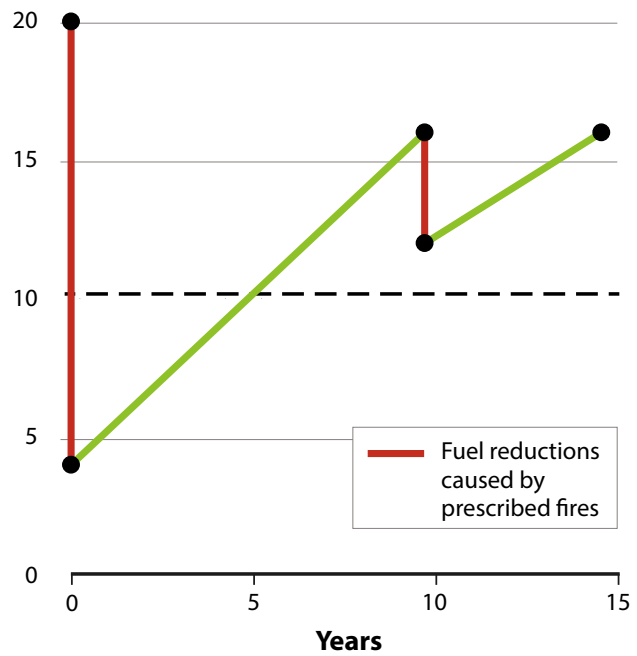

FIG. 1. Potential fuelload dynamics during a hypothetical prescribed burn program that includes burns in graphs (A), (B) and (C) at years 0,5 and 10 , and burns in graph (D) at years 0 and 10. The horizontal dashed line represents a possible target for desired fuel load, although the actual target will depend on objectives and fire-hazard factors. In these scenarios, graphs (A) and (B) achieve objectives while graphs (C) and (D) do not. 
burns on the same site. Clearly, fuel will re-accumulate over time, but the rates of recovery for different sizes of fuel depend on the effects of the initial fire, the forest structural characteristics and the biophysical environment (Keane 2008). Repeated burning could successively reduce fuel loads by a similar amount each time, eventually having a ratcheting-down effect (fig. 1A). Alternatively, especially high consumption in an initial-entry burn could set the stage for repeated maintenance burns that maintain the desired low fuel levels (fig. 1B). Other patterns exist that could result in a burn program that is not effective in meeting reduction targets if, for example, initial burns do not consume enough fuel (fig. 1C) or the burning interval is not frequent enough to keep up with fuel recovery rates (fig. 1D).

\section{An analysis focused for fire managers}

In the work described here, we condense findings reported in a previous study of forest burns (Levine et al. 2020) and analyze the data in a new way to articulate specific management applications. We focus on three objectives: (1) highlight the relative importance of prefire fuel load, overstory species composition and largetree density in driving fuel consumption; (2) profile the measured trends in fuel load by size category across replicated first-, second- and third-entry burns; and (3) provide an example of how the timing of future repeat burns could be scheduled using our results of fuel change over time guided by principles of what we refer to as disturbance-regime-guided silviculture (DReGS).

\section{Blodgett Forest Research Station}

Prescribed burns in the Levine et al. (2020) study were done at Blodgett Forest Research Station (BFRS), a University of California-owned mixed-conifer forest located on the western slope of the Sierra Nevada in El Dorado County, California. Prescribed fire research at BFRS began in the mid-1980s and expanded dramatically in the early 2000s. Since 2007, prescribed fires have been conducted annually at BFRS to facilitate research, extension and education. The forest is 2,961 acres (1,199 hectares) in area and is located at approximately 4,400 feet (1,342 meters) in elevation. It is typical of the high-productivity band of mixed-conifer forest that occurs on the western slopes of the Sierra Nevada. Like other high-productivity forests in the range, stands at BFRS are capable of rapidly developing large fuel loads, thus becoming vulnerable to severe wildfires. The study location therefore represents forests that are a high priority for the use of prescribed fire with the specific objective of lowering fuel loads to reduce future wildfire severity.

\section{Fall burns, weather conditions}

Initial burns were conducted in three replicated stands in the fall of 2002. Prior to these initial burns, it had been at least 90 years since the last fire. An important context of these burns is that no mechanical treatments (chainsaws or heavy equipment operations) were conducted prior to the burns as a way to "prepare" for burning by altering the forest structure. Each stand was approximately the same size (40 acres [16 hectares]) and contained typical mixed conifer species (Douglasfir, incense-cedar, ponderosa pine, sugar pine, and white fir). The stands were burned again in 2009 and 2017 - each time in the fall. The exact timing of burns was determined by several factors typical of burning in California related to fall burning: (1) the issuance of a burn permit, (2) conducive weather and fuel conditions, and (3) predictions that fire behavior would meet objectives, that is, consume surface fuel without unacceptable risk of escape from stand perimeters and damage to overstory trees. Because the permitting windows for fall burns are particularly short regardless of the weather-window duration (York et al. 2020), there was extremely limited flexibility in ensuring that all three burns were done under similar conditions.

The amount of pre-burn precipitation plays an important role in driving fire behavior, especially in the fall. Prior to the initial burn, no precipitation had occurred in the BFRS stands. This resulted in low fuel moisture, a situation amenable to effective fuel consumption in forest structures with high tree density and large fuel loads, such as those at BFRS. In 2009 and 2017, precipitation (less than one inch) during the month prior to the burns occurred, causing the burns to be lower intensity. Our experience with burning at BFRS annually for the past 18 years suggests that, as a result of permit restrictions, burning in the fall following precipitation is more feasible than burning without precipitation. The sequence of an initial entry burn during dry conditions, followed by repeat burns under slightly wetter conditions, represents an ideal scenario, but it is dependent on an initial entry burn that could be considered as higher risk since it is on the hotter end of prescription burning. One strategy for managing this risk is to perform initial-entry burns overnight, when temperatures are lower, but this adds another layer of complexity to operations.

\section{Analyses of fuel dynamics}

Levine at al. analyzed forest stands prior to and following each burn to quantify changes in forest structure, tree species composition, understory plant cover, understory plant composition and fuel loads. To focus on management implications, we report here the analysis of the results in a digested form, and we add a second analysis that is of particular relevance for the planning of prescribed burn programs.

The objective of our first analysis was to determine which of the forest structural and species compositional factors were most important in predicting 
surface-fuel consumption at fine scales. This focused on the variability between 0.1 -acre sample plots that occurred within the 40 -acre stands. We selected $11 a$ priori factors that we knew from previous research and experience were most likely to influence surface fuel consumption. We used a model-selection procedure to pare down the 11 factors one at a time, starting with the most comprehensive model and eventually honing in on the model that was the most parsimonious. This iterative approach identifies the "best" model that includes only those factors most important in explaining surface-fuel consumption.

We identified four of the 11 factors that were not only important drivers of fuel consumption but are also controllable from a silvicultural perspective: total fuel load, live-tree basal area, percent canopy cover (percentage of the ground that is covered by tree crowns) and relative abundance of pine species. We also described the effect of burn number (i.e., first-entry versus second- or third-entry) on these factors, and the interaction between burn number and the proportion of live-tree basal area that was in the Pinus genus (ponderosa and sugar pine).

In our second analysis, we assessed the betweenburn trends in surface fuel across the burns as well as the net change in surface fuel at the end of the burns compared to the beginning. We grouped fuel into three categories according to management relevance (fig. 2). Fine fuels, which is litter and sticks up to three inches in diameter, including fuels that are classified into 1-hour, 10-hour and 100-hour size classes. These are the fuels that are typically considered to be the most important drivers of fire behavior (Albini 1976). The second category, duff, is decomposing organic debris on the forest floor that conventionally has not been considered a strong driver of fire behavior (Burgan and Rothermel 1984). However, it may play a larger role under more extreme burning conditions. Additionally, duff may be of special interest for ecological restoration goals because long-term fire suppression has resulted in especially large accumulations that can influence regeneration, soil processes (Keifer et al. 2006) and mixed-conifer tree mortality (Stephens and Finney 2002). Finally, we considered coarse wood (logs that are more than three inches in diameter), which may be of special interest for wildlife habitat (Knapp 2015).

In our statistical analysis, we used a multivariate repeated measures approach to detect changes in fuel loads over time and to see if the three fuel categories changed in different ways. We considered the net change in fuel, from pre-burn initial conditions to post third burn, as a robust assessment of burning effectiveness. We also assessed the fine-scale changes in fuel over time, including pre- and post-burn measurements of all three burns, in order to more closely profile the drops and recoveries in fuel between burns. We considered time as being significant (i.e., fuel decreased as a result of the burns) if $P<0.05$, and as being weakly

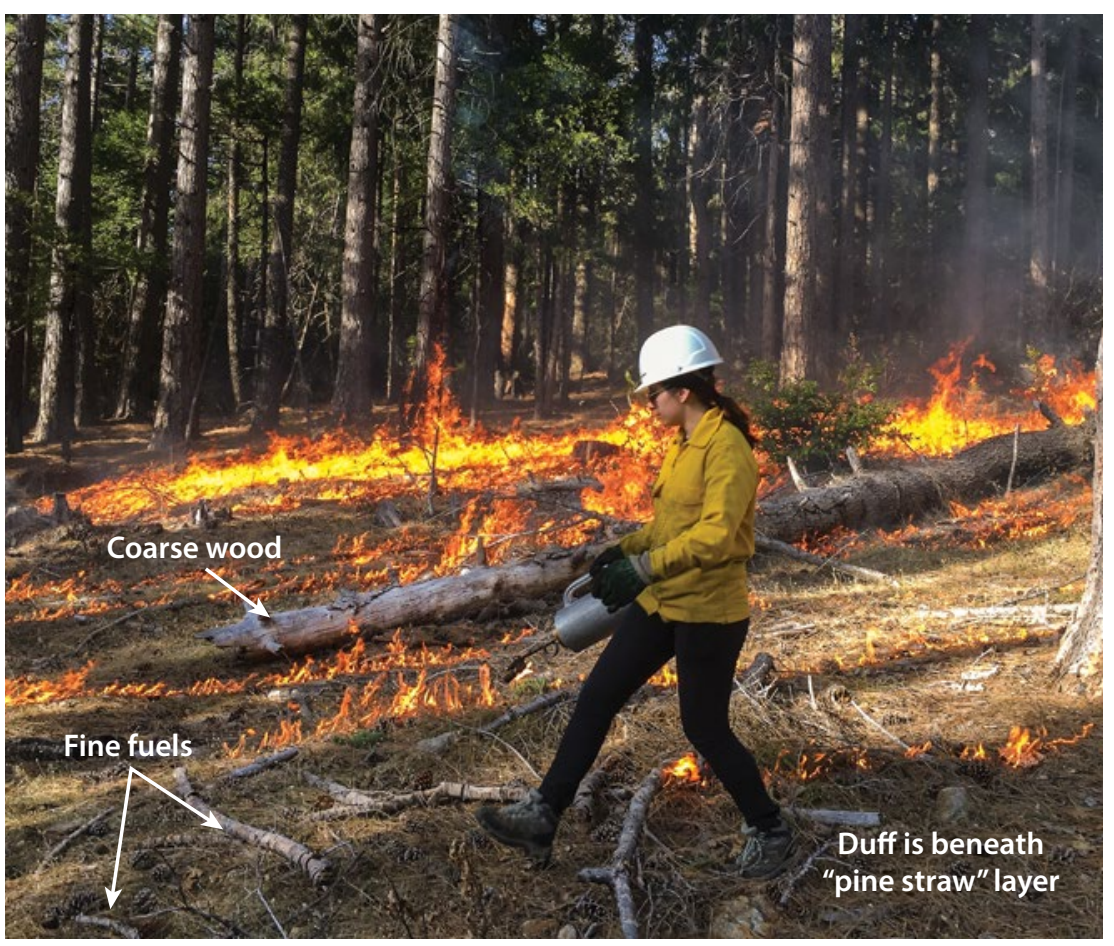

FIG. 2. A maintenance prescribed fire, occurring in winter. The open, pine-dominated structure in the foreground is allowing for consumption of fine fuels, but the fire is unlikely to consume large amounts of coarse wood and duff. The dense stand in the background requires relatively dry fuel conditions in order to consume the heavy fuels that are present. Photo: Rob York.
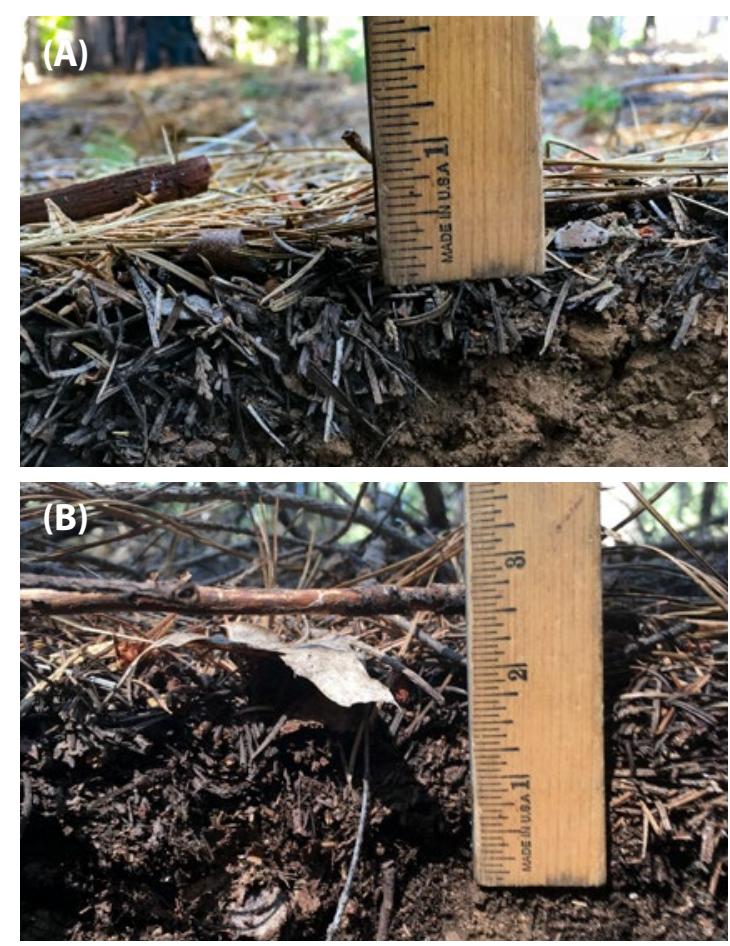

Profile of surface fuels in a stand burned three times in the past 18 years $(A)$ and a stand with thick duff and woody debris that has not burned in the past 100 years (B). One burn may not consume all of the fuel that is in stand $B$, but multiple burns may maintain lower fuel levels or progressively reduce fuel over time. Photos: Rob York. 


\section{Fine fuels}

20
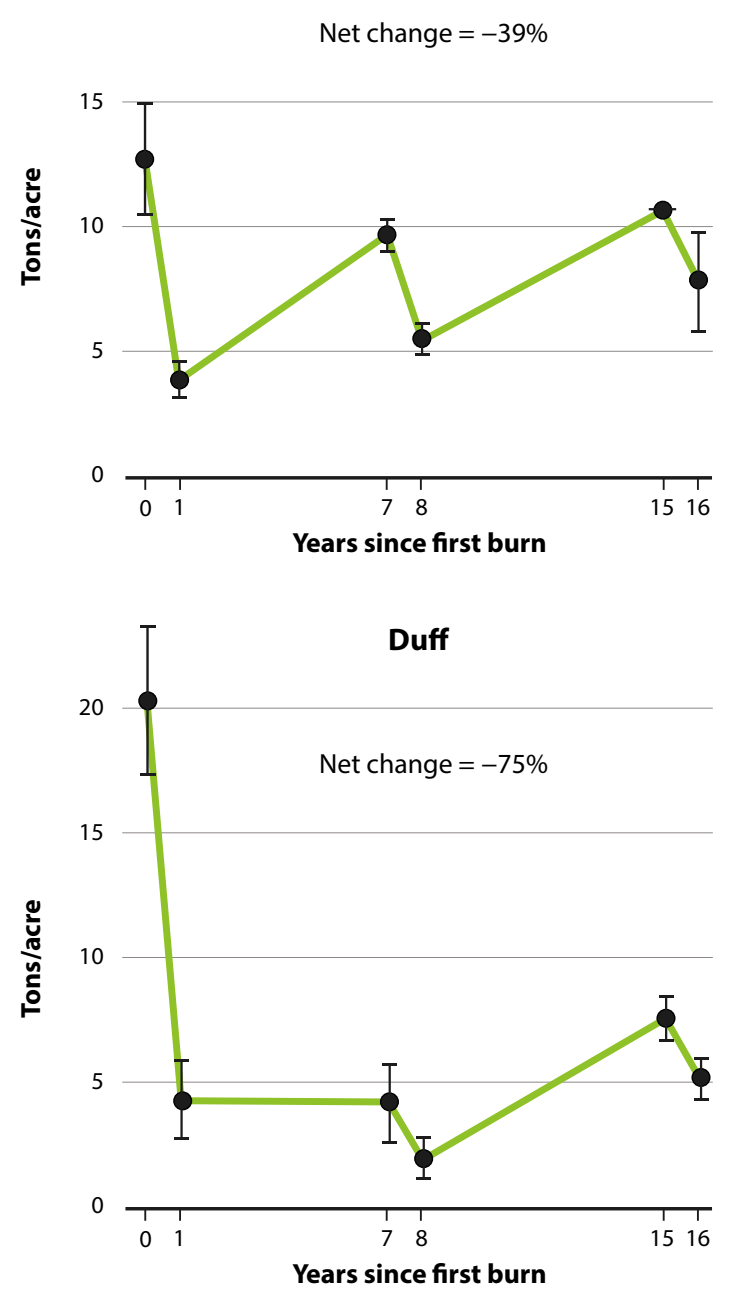

Coarse wood

20

Net change $=-56 \%$

15

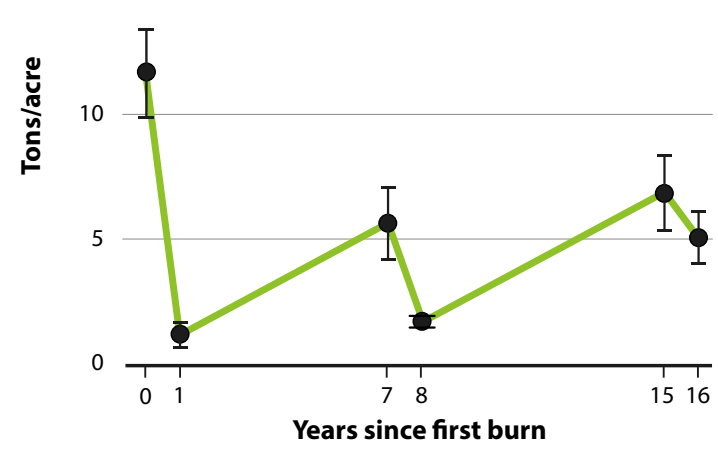

FIG. 3. Actual trends by fuel category across three prescribed burns in stands at Blodgett Forest Research Station. The first burns were not preceded by mechanical preparation treatments. Points are stand-level means; whiskers are standard errors. significant if $P<0.10$. We used the same $P$-value thresholds for the interaction between fuel category and time, an interaction that detected non-parallel trends between fuel categories.

\section{Fuel load and pine abundance influence burns}

The two most important forest-structure factors driving fuel consumption were fuel load and percent of basal area that was pine. Fuel consumption (as a percentage of pre-fire fuel load) was higher at plots with high initial fuel loads. The percentage of pine basal area, which quantified the relative abundance of sugar pine and ponderosa pine in the overstory versus all other species, was clearly important in driving fuel consumption, but it was also more complex. The interaction between pine basal area and burn number suggested that more pine was associated with less consumption during the first burn. But for the second and third burns, the abundance of pine was strongly associated with more consumption. Specifically, in burns two and three, a $10 \%$ increase in pine basal area was associated with a $9.3 \%$ and $6.2 \%$ increase in fuel consumption, respectively. In the first burn, a $10 \%$ increase in pine basal area was associated with a $4.7 \%$ decrease in fuel consumption. The other significant, but less influential, factors were total basal area (the ground area covered by the crosssectional area of stems at 4.5 feet above the ground) and percent canopy cover. Fuel consumption was slightly greater at the plot level when there was more basal area or lower canopy cover.

As expected, there was a large and statistically significant $(P<0.001)$ net reduction in surface fuel across all fuel size categories at the stand level prior to the first burn and 15 years later following the third burn (fig. 3). The rate of reductions varied across the three different categories (i.e., they were non-parallel), as indicated by a weakly significant $(P=0.06)$ interaction between time and size category. When all measurement times were considered in the analysis (i.e., incorporating finer temporal scale changes between burns and not just before the first burn compared to after the third burn), the effect of time on fuel load was also weakly significant $(P=$ 0.09). The fluxes in fuel load between burns decreased the capacity to detect time's significance. Rather than a ratcheting down of fuel, the profile of the trend in fuels indicated a large reduction caused by the first burn, followed by recovery, and then smaller reductions during subsequent burns (most similar to the simplified conceptual model in fig. 1B). There was no evidence that the trends were different among the three fuel categories when including all of the between-burn variability $(P=0.83)$.

\section{Management implications}

Even in high-hazard forests with high tree densities and large fuel loads from a century of fire suppression, we demonstrate here that prescribed fire without preceding mechanical preparation treatments can effectively reduce surface fuels. Further, this can be done without excessive damage to canopy trees (e.g., Stephens and Moghaddas 2005). Burning in the late summer or early fall prior to significant precipitation can lead to an initial-entry burn like the one that occurred in this study, which greatly reduced fuel across all size categories. The large drop in fuel from the first burn was a dominant factor in the burn program's eventual success once the third burn occurred.

A significant challenge to this type of first-entry burn, however, is that windows of opportunity for high-consumption fall burning are either narrow or non-existent because of permitting constraints (York et al. 2020). Consequently, managers are forced to burn when fuel is wetter and humidity is higher. Under these marginal fuel-moisture and weather conditions, it becomes even more important to consider the ways in which forest structure can be managed prior to any burn in order to maximize burn effectiveness under a wide range of fuel and logistical conditions.

Relative overstory pine abundance and live-tree basal area were positively related to fuel consumption, while percent canopy cover was negatively related. All three of these factors can be manipulated through silvicultural treatments in the years or decades prior to burning, leading to structures and compositions that are 
more conducive to fuel consumption. Managing to increase pine in the overstory, especially ponderosa pine, increases "pine straw" litter, which tends to have a lower bulk density (van Wagtendonk et al. 1998) that is easier to burn under wetter conditions. Ponderosa pine needles also dry out faster than other conifer needles (Anderson et al. 1978), increasing the window of opportunity even after significant fall precipitation. Similar to the role of long-leaf pine litter in the southeastern United States (Mitchell et al. 2009), ponderosa pine litter is, in our experience, a dominant factor in conducting successful prescribed fires during wetter fuel conditions in mixed-conifer forests.

Over the long term, the relative abundance of pine can be increased using regeneration harvesting methods. These methods can create distinct canopy openings, the size of which do not necessarily need to be larger than one acre, to maximize recruitment rates in productive forests (York et al. 2004). Planting ponderosa pine, especially on ash substrates created from pile burns (York et al. 2009), can further increase rates of recruitment into the canopy. In the shorter term, during thinning treatments that precede prescribed fires, retention of pine in the overstory is especially important in facilitating future burns. Managing for increased ponderosa pine abundance is co-aligned with historical forest conditions in these forests and is often a stated restoration goal for mixed-conifer forests.

The different effects of live-tree basal area, which was positively related to fuel consumption, and canopy cover, which was inversely related, is not intuitive. Basal area and canopy cover are generally related to each other in a positive but nonlinear way. The stands in this study were dominated by large trees, especially after the second and third burns. Because much of the wood in large trees is heartwood, which is not correlated with leaf area, a stand with low stem density can be high in basal area yet have a somewhat open canopy. For this to occur, the structure must be dominated by sparse but large trees. Integrating the results suggests that stand structures characterized by low-density, large pine trees present the ideal overstory structure for prescribed burning to reduce and maintain low surface fuel.

\section{Determining burn frequency}

If prescribed burning becomes more common in mixed-conifer forests, an emerging challenge faced by managers will be to decide which type of burn initial or repeat - to prioritize during limited burn windows. This study suggests that if conditions are dry and there is an opportunity to burn, it is worthwhile to prioritize first-entry burns. During wetter conditions, resources may be better spent on maintenance burns, or on initial-entry burns where forest structure and composition have been managed specifically to facilitate prescribed burning. Ideally, a manager has all three types of prescribed burns (initial entry, maintenance and burns in stands where the canopy density has been reduced and ponderosa pine favored) ready in each burn season.

A fundamental responsibility for managers of prescribed-burn programs is determining the frequency of follow-up burns. The question of burning frequency is one currently faced by the authors of this study as we consider the timing of a fourth burn in the BRFS stands. A broad objective of future burns for this longterm study is that they represent maintenance burns likely to be prescribed for California forests. However, burn programs that focus on specific objectives, such as timber yield or carbon, versus those that focus on process restoration have different conceptual frameworks and may have different implications for burn frequency. To demonstrate the varied approaches, we discuss below three alternative frameworks for guiding our decision about when to plan the next burn in the BRFS stands.

1. Range of natural variability $(R N V)$. In terms of fire frequency, RNV is a reconstructed maximum range of fire-return interval that can be used to demonstrate the extent that contemporary forests have departed from those of the past (Battles et al. 2013). The RNV for fire frequency can be used as a target, where management is deemed successful if the fires occur at a frequency that is less than the maximum range that was thought to occur in the past, prior to the current era of fire suppression. The reconstructed fire regime at BFRS suggests a frequency range of from two to 29 years (Stephens and Collins 2004). The benefit of this approach is that it provides a simple and quantitative metric. Further, it provides ample flexibility (in this case, 27 years) for meeting the target. Arguably, however, neither the maximum nor the minimum fire-return intervals are suitable targets for long-run fire frequency. Historically, most fires would have occurred less than 29 (but more than two) years apart. Understanding the distribution frequency of past fire-return intervals may help target a distribution of desired prescribed-fire frequency, but reconstruction studies of fire frequency do not typically provide this level of precision. Further, reconstructions of fire frequency are based only on physical evidence of fire scars that are visible in tree rings. Because low-intensity fires do not necessarily cause a fire scar, RNV is an overestimate of the actual fire frequency that occurred.

2. Fuel and fire hazard monitoring. The second approach that we considered is more objective-based, where a decision to burn is triggered by close monitoring of fuels against some management target for wildfire resistance (e.g., Keifer et al. 2006). This requires frequent measurements of fuel and forest structure, using modeling to determine likely severity in the event of a wildfire. This approach includes associated thresholds for modeled overstory mortality under wildfire conditions. For example, managers might decide to burn only if forest structure has
A fundamental responsibility for managers of prescribedburn programs is determining the frequency of follow-up burns. 

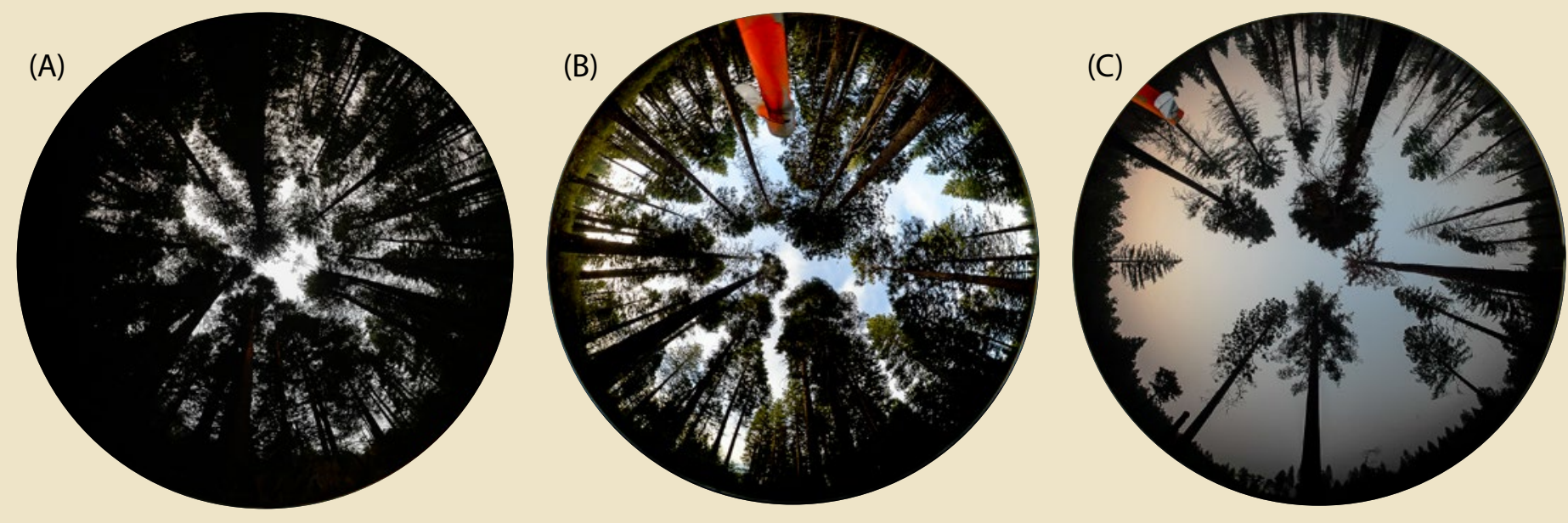

Hemispherical

photographs of canopies of $(A)$ a stand that has not been thinned or burned for 100 years, (B) a stand that was burned three times in the past 18 years, and $(C)$ a stand that was thinned and burned twice in the past 18 years. Our data suggest that surface fuel consumption during a prescribed fire is likely to be greatest in stand $C$ and the least in stand A. Photos: Rob York. developed to the point where a wildfire occurring on a hot summer day is predicted to cause more than $50 \%$ mortality of overstory trees. While this approach could result in an efficient strategy for reducing wildfire hazard, depending upon the accuracy of its models, it is narrowly focused on a single metric. It does not consider all of the unknown ecological benefits that would come from restoring fire frequency and the complex spatial patterns in forest overstory and understory patterns that have been demonstrated in historical mixed-conifer forests (Collins et al. 2015; Lydersen et al. 2013). Further, this approach requires a high-frequency monitoring program that would likely be cost-prohibitive in most management scenarios.

3. Disturbance-regime-guided silviculture (DReGS). This approach takes lessons from disturbance ecology, applying the concept that management should emulate ecosystem patterns and processes as much as possible (e.g., Seymour et al. 2002). While typically applied to timber harvests, this approach could also be applied to prescribed fire, which, like timber harvesting, is a silvicultural practice. Given climatic changes, safety concerns and potential liability realities associated with using fire in California, we highlight the term guided in our definition, which is meant to recognize the impracticality of precisely knowing and then mimicking the past disturbance regime given realistic operational constraints. Replicating a target fire frequency with high precision can be especially difficult because planned burns are often delayed (Miller et al. 2020). Use of the term silviculture is also essential to the application of this concept because it implies the importance of meeting specific societal or landowner objectives in treating forests. As with RNV, an advantage of this approach is being able to quantify a target for management. By incorporating flexibility for social constraints and by attempting to meet specific objectives, it has the important and added advantage of management flexibility. The downside is the risk of being so flexible and accommodating of logistical constraints that ecological benchmarks no longer apply.

Given the objectives and constraints at the BRFS study location, we decided that the DReGS concept is the most promising approach to use in planning a fourth burn. The median fire frequency in the study area was reconstructed to be less than 5 to 10 years at the stand scale (Stephens and Collins 2004). Applying the concept of DReGS, we would use this 5- to 10year target as a starting point and then adjust it into an achievable schedule that allows for uncertainty in operational variables (e.g., not being able to get a burn permit because of weather conditions). Using information from our study about fuel recovery between burns, we can also ensure that we meet management objectives (e.g., not allowing fuel to recover to pre-burn levels). In the BRFS stands, which are productive in producing surface fuel and where there is therefore an abundant supply of pine litter input, the data suggest that it is feasible to burn effectively every 5 years in order to maintain low levels of surface fuel. However, it is unlikely that a precise 5 -year schedule will actually be attainable because of difficulties in getting permits that coincide in time with low fuel-moisture levels necessary for effective burns. Hence, a burn-frequency plan with a hedge-betting element would be to aim for conducting the next burn after 5 years (specifically, fall of 2022) if conditions are adequate. It is acceptable to burn sooner if conditions are appropriate, or to delay burning a year at a time until a maximum of 10 years after the last burn, which would, in this case, mean burning by the fall of 2026. Further delays would depart unacceptably from the ecosystem's disturbance regime and also risk returning to pre-fire fuel loads, especially in the finefuel category. If this were to happen, we would consider the burn program to no longer be effective within the DReGS conceptual framework. 


\section{New tools and challenges}

As prescribed-burn programs across California develop with time, new silvicultural tools for managing forests to enhance future burn effectiveness will likely be needed. Our study, for example, suggests that guidelines for managing ponderosa pine needle input onto the forest floor could be helpful. Existing information about leaf area in standing trees, needle cast distance and needle input/decomposition rates could be integrated to manage pine-tree density and spatial arrangement so that pine-needle litter on forest floors is maintained or optimized to carry low-intensity prescribed fires. Also important will be the identification of feedbacks that occur between the litter that overstory compositions create and the resulting fire behavior influenced by that litter, and an analysis of how these feedbacks might affect the resulting overstory composition in the future. This "ecology of fuels" concept (Mitchell et al. 2009) could be a useful framework for identifying applied-research needs for prescribed burning in California.

Finally, our study highlights the challenges and importance of being flexible and of taking the long view when developing prescribed-burn programs. Management decisions for the decades preceding burns, being ready to burn during limited periods of conducive weather in all seasons and being adaptive in scheduling future burns are all critical factors that forest managers must consider in planning burn programs that span multiple decades. CA

R.A York is Assistant Cooperative Extension Specialist, UC Berkeley; J. Levine is Graduate Student, Princeton University; D. Foster is Graduate Student, UC Berkeley; S. Stephens is Professor, UC Berkeley; B. Collins is Adjunct Professor, UC Berkeley.

\section{References}

Albini FA. 1976. Estimating wildfire behavior and effects. USDA Forest Service, Intermountain Forest and Range Experiment Station, General Technical Report INT-30.

Anderson HE, Schuette RD, Mutch RW. 1978. Timelag and equilibrium moisture content of ponderosa pine needles. USDA Forest Service, Intermountain Forest and Range Experiment Station, Research Paper INT-202.

Battles JJ, Moody TJ, Saah D. 2013. Natural Resource Conditions Assessment, Sequoia \& Kings Canyon National Parks 4.21: Assessment of Altered Fire Regimes. Natural Resource Report NPS/SEKI/NRR2013/665.21

Burgan RE, Rothermel RC. 1984. BEHAVE: fire behavior prediction and fuel modeling system-FUEL subsystem. USDA Forest Service General Technical Report INT-167.

Cal Fire 2018. CAL FIRE jurisdiction fires, acres, dollar damage, and structures destroyed. California Department of Forestry and Fire Protection. Sacramento Calif.

Collins BM, Lydersen JM, Everett $R G$, et al. 2015. Novel characterization of landscape-level variability in historical vegetation structure. Ecol Appl 25:1167-74. https://doi.org/10.1890/14 1797.

Keane RE. 2008. Biophysical Controls on Surface Fuel Litterfall and Decomposition in the Northern Rocky Mountains, USA. Can J For Res 38(6):143145. https://doi.org/10.1139/ X08-003

Keifer M, van Wagtendonk JW, Buhler M. 2006. Long-term surface fuel accumulation in burned and unburned mixedconifer forests of the central and southern Sierra Nevada, CA (USA). Fire Ecol 2(1):53-72. https://doi.org/10.4996/fireecology.0201053

Knapp EE, Keeley JE, Ballenger EA, Brennan TJ. 2005. Fuel reduction and coarse woody debris dynamics with early season and late season prescribed fire in a Sierra Nevada mixed conifer forest. For Ecol Manag 208:38397. https://doi.org/10.1016/j. foreco.2005.01.016

Knapp EE. 2015. Long-term dead wood changes in a Sierra Nevada forest: Habitat and fire hazard implications. For Ecol Manag 339:87-95. https://doi.org/10.1016/j. foreco.2014.12.008

Levine JI, Collins BM, York RA Foster, DE, et al. 2020. Forest stand and site characteristics influence fuel consumption in repeat prescribed burns. Int J Wildland Fire 29(2):148-59. https://doi.org/10.1071/ WF19043
Lydersen, JM, North MP, Knapp EE, and Collins BM. 2013. Quantifying spatial patterns of tree groups and gaps in mixed-conifer forests: reference conditions and long-term changes following fire suppression and logging. For Ecol Manag 304:370-82. https://doi.org/10.1016/j. foreco.2013.05.023

Miller C, Urban DL. 2000. Connectivity of forest fuels and surface fire regimes. Landscape Ecol 15:145-54. https://doi. org/10.1023/A:1008181313360

Miller RK, Field, CB, Mach KJ. 2020. Barriers and enablers for prescribed burns for wildfire management in California. Nat Sustainability 3:101-9. https:// doi.org/10.1038/s41893-019. 0451-7

Mitchell RJ, Hiers K, O'Brien J, Starr G. 2009. Ecological forestry in the Southeast: Understanding the ecology of fuels. J For 107(8):391-97.

Ryan KC, Knapp EE, Varner JM 2013. Prescribed fire in North American forests and woodlands: history, current practice, and challenges. Front Ecol Environ 11:15-24. https://doi. org/10.1890/120329

Scholl AE, Taylor AH. 2010. Fire regimes, forest change, and self-organization in an oldgrowth mixed-conifer forest, Yosemite National Park, USA Ecol Appl 20:362-80. https:// doi.org/10.1890/08-2324.1
Seymour RS, White AS, deMaynadier PG. 2002. Natural disturbance regimes in northeastern North America - evaluating silvicultural systems using natural scales and frequencies. For Ecol Manag 155:357-67. https://doi.org/10.1016/S03781127(01)00572-2

Stephens SL, Finney MA. 2002. Prescribed fire mortality of Sierra Nevada mixed conifer tree species: Effects of crown damage and forest floor combustion. For Ecol Manag 162:261-71. https:// doi.org/10.1016/S0378

1127(01)00521-7

Stephens SL, Collins BM. 2004 Fire regimes of mixed conifer forests in the north-central Sierra Nevada at multiple spatia scales. Northwest Sci 78:12-23.

Stephens SL, Moghaddas JJ. 2005. Experimental fuel treatment impacts on forest struc ture, potential fire behavior and predicted tree mortality in a California mixed conifer forest. For Ecol Manag 215:21-36. https://doi.org/10.1016/j. foreco.2005.03.070

Taylor AH, Vandervlugt AM, Maxwell RS, Beaty RM, et al. 2013 Changes in forest structure, fuels and potential fire behaviour since 1873 in the Lake Tahoe Basin, USA. Appl Veg Sci 17:17-31. https://doi. org/10.1111/avsc.12049

Vaillant N, Fites-Kaufman J, Stephens SL. 2009. Effectiveness of prescribed fire as a fuel treatment in Californian coniferous forests. Int Journal Wildland Fire 18:165-75. https://doi. org/10.1071/WF06065 van Wagtendonk JW, Benedict JM, Sydoriak WM. 1998. Fuel bed characteristics of Sierra Nevada conifers. J Appl For 13:73-84. https:/doi.org/10.1093/ wjaf/13.3.73

Webster KM, Halpern CB. 2010. Long-term vegetation responses to reintroduction and repeated use of fire in mixedconifer forests of the Sierra Nevada. Ecosphere 1:1-27. https:// doi.org/10.1890/ES10-00018.1

York RA, Heald RC, Battles JJ, York JD. 2004. Group selection management in conifer forests: relationships between opening size and tree growth. Can $J$ For Res 34:630-41. https://doi. org/10.1139/x03-222

York, RA, Thomas Z, Restaino J. 2009. Influence of ash substrate proximity on growth and survival of planted mixedconifer seedlings. West J Appl For 24(3):117-23. https://doi. org/10.1093/wjaf/24.3.117

York RA, Roughton A, Tompkins R, Kocher S. 2020. Outlook: Burn permits need to facilitate - not prevent - "good fire" in California. Calif Agr 74(2):62-6. https:// doi.org/10.3733/ca.2020a0014

Fernandes PM, Botelho HS.

2003. A review of prescribed

burning effectiveness in fire

Fire 12:117-28. https://doi.

org/10.1071/WF02042 